\title{
Assessment of effective orifice area of prosthetic aortic valves with Doppler echocardiography: An in vivo and in vitro study
}

\author{
Odd Bech-Hanssen, MD, PhDa \\ Kenneth Caidahl, MD, PhDa \\ Ingemar Wallentin, MD, PhDa \\ Per Ask, PhD ${ }^{\mathrm{b}}$ \\ Bengt Wranne, MD, $\mathrm{PhD}^{\mathrm{c}}$
}

From the Department of Clinical Physiology, Sahlgrenska University Hospital, ${ }^{\mathrm{a}}$ and the Departments of Biomedical Engineering ${ }^{\mathrm{b}}$ and Clinical Physiology, ${ }^{c}$ Linköping University Hospital, Göteborg, Sweden.

This study was supported by Vingmed GE Sound, Horten, Norway, and by grants from the Göteborg Medical Society, Sahlgrenska University Hospital, the Swedish Heart and Lung Foundation, Swedish Medical Society, St Jude Medical, Inc, St Paul, Minn, MedicalCV, Incorporated, Inver Grove Heights, Minn, and Västra Götalandregionen.

Received for publication Dec 19, 2000; revisions requested Jan 22, 2001; revision received Feb 5, 2001; accepted for publication Feb 12, 2001.

Address for reprints: Odd Bech-Hanssen, MD, PhD, Department of Clinical Physiology, Sahlgrenska University Hospital, SE41345 Göteborg, Sweden (E-mail: odd.bechhanssen@klinfys.gu.se).

J Thorac Cardiovasc Surg 2001;122:287-95

Copyright (C) 2001 by The American Association for Thoracic Surgery

0022-5223/2001 $\$ 35.00+0 \quad \mathbf{1 2 / 1 / 1 1 5 1 6 1}$

doi:10.1067/mtc.2001.115161
Objectives: We sought to evaluate the Doppler assessment of effective orifice area in aortic prosthetic valves. The effective orifice area is a less flow-dependent parameter than Doppler gradients that is used to assess prosthetic valve function. However, in vivo reference values show a pronounced spread of effective orifice area and smaller orifices than expected compared with the geometric area.

Methods: Using Doppler echocardiography, we studied patients who received a bileaflet St Jude Medical valve ( $\mathrm{n}=75$; St Jude Medical, Inc, St Paul, Minn) or a tilting disc Omnicarbon valve $(n=46$; MedicalCV, Incorporated, Inver Grove Heights, Minn). The prosthetic valves were also investigated in vitro in a steadyflow model with Doppler and catheter measurements in the different orifices. The effective orifice area was calculated according to the continuity equation.

Results: In vivo, there was a wide distribution with the coefficient of variation $(\mathrm{SD} /$ mean $\times 100 \%)$ for different valve sizes ranging from $21 \%$ to $39 \%$ in the St Jude Medical valve and from $25 \%$ to $33 \%$ in the Omnicarbon valve. The differences between geometric orifice area and effective orifice area in vitro were $1.26 \pm 0.41$ $\mathrm{cm}^{2}$ for St Jude Medical and $1.17 \pm 0.38 \mathrm{~cm}^{2}$ for Omnicarbon valves. The overall effective orifice areas and peak catheter gradients were similar: $1.35 \pm 0.37 \mathrm{~cm}^{2}$ and $25.9 \pm 16.1 \mathrm{~mm} \mathrm{Hg}$ for St Jude Medical and $1.46 \pm 0.49 \mathrm{~cm}^{2}$ and $24.6 \pm 17.7 \mathrm{~mm}$ $\mathrm{Hg}$ for Omnicarbon. However, in St Jude Medical valves, more pressure was recovered downstream, $11.6 \pm 6.3 \mathrm{~mm} \mathrm{Hg}$ versus $3.4 \pm 1.6 \mathrm{~mm} \mathrm{Hg}$ in Omnicarbon valves $(P=.0001)$.

Conclusions: In the patients, we found a pronounced spread of effective orifice areas, which can be explained by measurement errors or true biologic variations. The in vitro effective orifice area was small compared with the geometric orifice area, and we suspect that nonuniformity in the spatial velocity profile causes underestimation. The St Jude Medical and Omnicarbon valves showed similar peak catheter gradients and effective orifice areas in vitro, but more pressure was recovered in the St Jude Medical valve. The effective orifice area can therefore be misleading in the assessment of prosthetic valve performance when bileaflet and tilting disc valves are compared.

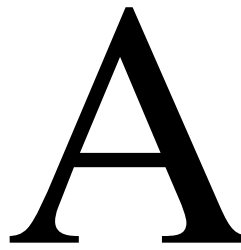

Doppler echocardiographic investigation is now frequently used as part of the follow-up for patients with prosthetic heart valves. Studies of long-term survival in patients undergoing aortic valve replacement reveal excess mortality when these patients are compared with the background population. ${ }^{1,2}$ Prosthetic valve function is one of the important determinants for the outcome of aor- 


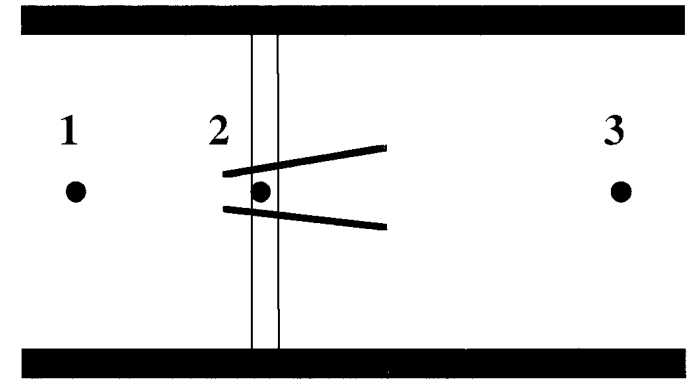

1

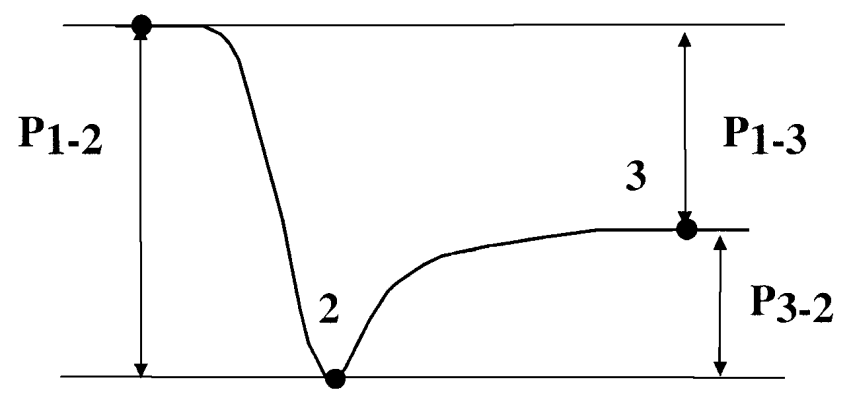

$P_{1-2}$ : Peak catheter gradient

$\mathrm{P}_{3}$ 2: Pressure recovery

P1-3: Net catheter gradient

Figure 1. Schematic representation of a pullback pressure recording in the central orifice of a St Jude Medical prosthetic valve from the ventricular chamber (1) to the aorta (3). Calculations of peak catheter gradients, pressure recovery, and the net pressure gradient are illustrated.

tic valve replacement. In mechanical prosthetic valves, tissue ingrowth or thrombus formation might cause obstruction. Furthermore, in some patients with a large body size relative to the aortic root or in physically active individuals, a normally functioning prosthetic valve can cause an obstruction of hemodynamic importance. ${ }^{3}$

In prosthetic aortic valves, the detection of prosthesis dysfunction and the assessment of hemodynamic performance are complicated by the flow dependence of Doppler gradients. The occurrence of local high velocities and pressure recovery, especially in bileaflet valves, further limits the usefulness of Doppler gradients. ${ }^{4,5}$ In mechanical prosthetic valves, the effective orifice area (EOA) of the valve can be assumed to be independent of flow, ${ }^{6}$ and the use of the EOA in prosthetic valve function assessment is recommended. ${ }^{7}$ When blood accelerates through a prosthesis, the bloodstream contracts; the EOA, which corresponds to the vena contracta, can therefore be expected to be a fraction less than the geometric orifice itself. ${ }^{8}$ However, in vivo Doppler echocardiographic reference values for prosthetic valves show a pronounced spread of EOA within the same valve size group, and the EOA tends to be smaller than expected compared with the geometric orifice area. ${ }^{9-11}$

We hypothesized that the previously observed pronounced spread of EOA in vivo was caused by measurement errors. We therefore performed an in vitro study in which these errors were minimized. The aims of the study were to evaluate the Doppler echocardiographic assessment of EOA. Further, we evaluated the relationship between valve EOA, design, and hemodynamic performance.

\section{Methods \\ Valve Design}

The St Jude Medical (SJM) standard valve (St Jude Medical, Inc, St Paul, Minn) is a bileaflet pyrolytic carbon valve with an $85^{\circ}$ leaflet angle in the open position. The two-leaflet occluder design divides the area available for forward flow into three regions, one central and two side orifices. The tilting disc Omnicarbon (OMNI) valve (MedicalCV, Incorporated, Inver Grove Heights, Minn) consists of pyrolytic carbon with a maximum opening angle of $80^{\circ}$. The area available for forward flow is divided into a major and a minor orifice.

\section{The Proportion of the Forward Flow Entering Different Orifices}

To estimate the proportion of forward flow entering different orifices, we calculated the orifice areas separately. The full orifice areas and the separate areas were determined by planimetry using NIH Image 1.62 software (National Institutes of Health, Bethesda, $\mathrm{Md}$ ). The proportion of the forward flow entering different orifices was assumed to correspond to the area proportion.

\section{In Vitro Study}

Model. Prosthetic valves were mounted in an in vitro flow model described previously, ${ }^{5}$ producing a continuous flow of between 178 and $395 \mathrm{~mL} / \mathrm{s}$. The model consisted of a circular ventricular chamber $(78 \times 46 \mathrm{~mm})$ with a conically shaped outflow tract and a circular aortic chamber $(93 \times 36 \mathrm{~mm})$. Flow entered the ventricular chamber by gravity from an upper reservoir, and different flow levels were obtained by changing the reservoir model height. The model was designed with the largest resistance at the entrance to the ventricular chamber, thereby promoting uniformity of flow. Corn starch was added to the fluid to facilitate Doppler measurements (water $70 \%$ and glycerol $30 \%$, temperature $21^{\circ} \mathrm{C}$, and viscosity $3 \times 10^{-3} \mathrm{~ns} / \mathrm{m}^{2}$, ie, similar to whole blood).

Flow was measured with an ultrasonic flowmeter (HT 109; Transonic Systems, Inc, Ithaca, NY). The validity of the system was tested by series of timed collections. The flowmeter accurately predicted the flow $(y)$ rates calculated from timed collections $(y=1.018 x+5.7 ; r=0.99, P=.0001)$.

Test protocol. Five sizes (19, 21, 23, 25, and $27 \mathrm{~mm})$ of SJM and OMNI prostheses were tested at 7 different flow rates. The flow rates were increased with increasing valve size to mimic 


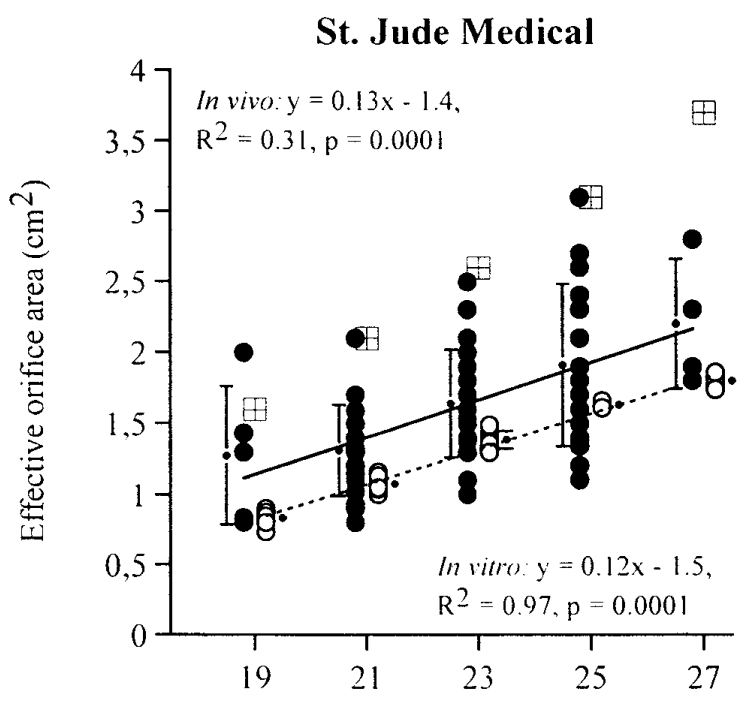

Valve size $(\mathrm{mm})$

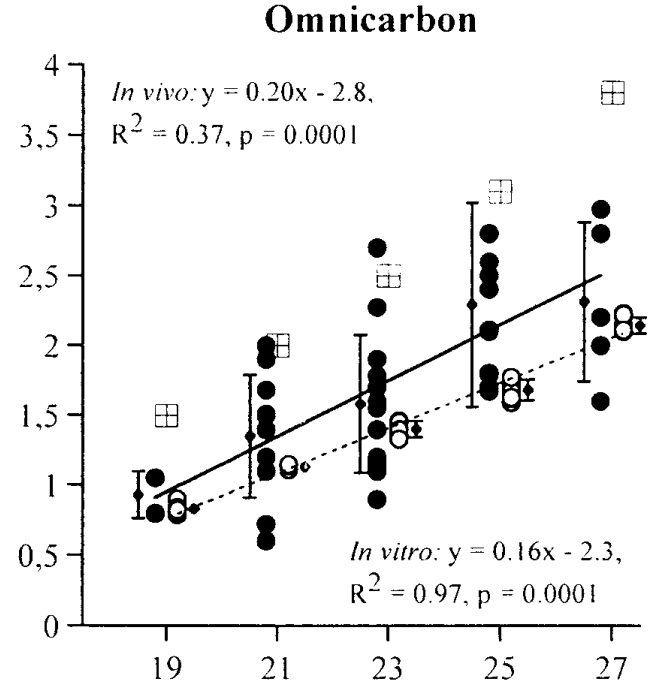

Valve size $(\mathrm{mm})$

Figure 2. Distribution of EOA grouped by prosthesis size of the St Jude Medical (left) and Omnicarbon (right) valves. Results are shown for the in vivo $(\bullet)$ and in vitro $(\bigcirc)$ studies. Bars indicate mean \pm SD. Boxes show the geometric orifice area.

physiologic conditions. At each flow level, 3 catheter pullback maneuvers were performed with the aim of identifying the maximum pressure decrease in the central and side orifices of the SJM valve and the major and minor orifices of the OMNI valve. A continuous wave Doppler investigation of the different orifices was performed twice at each flow rate.

Pressure measurements. Aortic and ventricular pressures were recorded with fluid-filled stainless steel catheters (outer diameter $1.50 \mathrm{~mm}$ and inner diameter $1.00 \mathrm{~mm}$ ) connected to electronic pressure transducers (PRCR 75 S/D 889; Druck Ltd, Leicester, United Kingdom) and a pressure recorder system (Gould WindoGraf; Gould Instrument Systems, Valley View, Ohio). The catheter had a side-hole orifice $3 \mathrm{~mm}$ from the catheter tip. This design of the catheter eliminates the dynamic pressure component. It was pulled back manually from a ventricular position approximately $10 \mathrm{~mm}$ from the plane of the first structure in the prosthesis (0-level) to a position approximately $65 \mathrm{~mm}$ from the 0 -level on the aortic side. The pressure gradients were measured between the start position on the ventricular side and at different locations in the prosthesis and aorta during pullback. Figure 1 shows a schematic representation of a pullback pressure recording in the central orifice of the SJM valve.

Doppler echocardiography. Doppler velocity measurements were obtained with a Vingmed System 5 (Vingmed Sound AS, Horten, Norway) with a $3.5-\mathrm{MHz}$ ultrasound transducer. The transducer was positioned on the ventricular chamber side of the model at a distance of $78 \mathrm{~mm}$ from the prostheses. To facilitate the separation of the maximum velocities in the different orifices, we improved the lateral resolution by changes in the software of the ultrasound machine.

Doppler measurements. The Doppler tracings were stored on $\mathrm{S}$-VHS videotapes and compact disks and analyzed off-line in the
Echopac computer program (Vingmed Sound AS). The spectral display from pulsed and continuous wave Doppler recordings was digitized along its outer border, giving the velocity time integral (VTI).

\section{In Vivo Study}

The present study presents data from 121 patients who participated in a study that has previously been described in detail. ${ }^{10}$ The patients were investigated after aortic valve replacement (median 5 days postoperatively, range 2-35 days). The bileaflet SJM valve was inserted in 75 patients, and the tilting disc OMNI valve was used in 46 patients. Informed consent was obtained from all patients, and the study was approved by the human ethics committee at Sahlgrenska University Hospital.

Two-dimensional echocardiography. Echocardiography was performed with an Acuson 128 or 128 XP Computed Sonograph (Acuson, Mountain View, Calif). From a parasternal long-axis position, we obtained a digital cine loop of an enlarged view of the left ventricular outflow tract (LVOT). Using electronic calipers, we measured the diameter just below the aortic valve from the trailing edge of the anterior echo to the leading edge of the posterior echo. ${ }^{12}$

Doppler measurements. Blood flow velocity in the LVOT $\left(\mathrm{V}_{\text {LVOT }}\right)$ was estimated by pulsed wave Doppler echocardiography from an apical window (sample axial volume size of $5 \mathrm{~mm}$ ). Continuous wave Doppler signals were recorded by a 2-MHz nonimaging probe. Continuous wave Doppler recordings of the jet velocity through the prosthetic valve were obtained only from an apical window for practical reasons (difficulty changing the position of the patients, bandages). The velocity profiles were recorded on paper and traced along the outer border of the spectral display by means of a digitizing table (Summagraphics 
TABLE 1. In vitro EOAs and discharge coefficients calculated according to the continuity equation

\begin{tabular}{|c|c|c|c|c|c|}
\hline & \multicolumn{5}{|c|}{ Size (mm) } \\
\hline & 19 & 21 & 23 & 25 & 27 \\
\hline & \multicolumn{5}{|c|}{ SJM } \\
\hline Geometric orifice area & 1.6 & 2.1 & 2.6 & 3.1 & 3.7 \\
\hline $\mathrm{EOA}_{\text {Peak }}$ & $0.83 \pm 0.06$ & $1.08 \pm 0.05$ & $1.39 \pm 0.06$ & $1.63 \pm 0.02$ & $1.80 \pm 0.04$ \\
\hline $\mathrm{EOA}_{\text {Separate }}$ & $0.87 \pm 0.08$ & $1.16 \pm 0.04$ & $1.57 \pm 0.06$ & $1.78 \pm 0.08$ & $2.02 \pm 0.04$ \\
\hline$P$ value & .056 & .0002 & .0001 & .015 & .0001 \\
\hline Discharge $_{\text {Peak }}$ & $0.52 \pm 0.04$ & $0.51 \pm 0.03$ & $0.53 \pm 0.02$ & $0.53 \pm 0.01$ & $0.49 \pm 0.01$ \\
\hline Discharge $_{\text {Separate }}$ & \multicolumn{5}{|c|}{ OMNI } \\
\hline Geometric orifice area & 1.6 & 2 & 2.5 & 3.1 & 3.8 \\
\hline $\mathrm{EOA}_{\text {Peak }}$ & $0.83 \pm 0.04$ & $1.13 \pm 0.02$ & $1.39 \pm 0.06$ & $1.68 \pm 0.07$ & $2.16 \pm 0.06$ \\
\hline $\mathrm{EOA}_{\text {Separate }}$ & $0.83 \pm 0.03$ & $1.13 \pm 0.01$ & $1.40 \pm 0.05$ & $1.67 \pm 0.07$ & $2.15 \pm 0.06$ \\
\hline$P$ value & .10 & .47 & .70 & .28 & .81 \\
\hline Discharge $_{\text {Peak }}$ & $0.55 \pm 0.03$ & $0.57 \pm 0.01$ & $0.56 \pm 0.02$ & $0.54 \pm 0.02$ & $0.57 \pm 0.02$ \\
\hline Discharge $_{\text {Separate }}$ & $0.55 \pm 0.02$ & $0.56 \pm 0.01$ & $0.56 \pm 0.02$ & $0.54 \pm 0.02$ & $0.57 \pm 0.02$ \\
\hline
\end{tabular}

Five valve sizes were tested at 7 different flow rates. Mean \pm SD. EOA, Effective orifice area; Discharge, discharge coefficient. $P$ value for comparison between $\mathrm{EOA}_{\text {Peak }}$ and $\mathrm{EOA}_{\text {Separate }}$

TABLE 2. Catheter pressure gradients in the SJM and OMNI valves

\begin{tabular}{llcl}
\hline & \multicolumn{1}{c}{ SJM } & OMNI & P value \\
\hline Peak catheter gradient $(\mathrm{mm} \mathrm{Hg})$ & $25.9 \pm 16.1$ & $24.6 \pm 17.7$ & .74 \\
Net catheter gradient $(\mathrm{mm} \mathrm{Hg})$ & $14.4 \pm 10.8$ & $21.2 \pm 16.5$ & .05 \\
Recovered pressure $(\mathrm{mm} \mathrm{Hg})$ & $11.6 \pm 6.3$ & $3.4 \pm 1.6$ & .0001 \\
Percent recovered pressure & $48.1 \pm 12.2$ & $17.6 \pm 7.2$ & .0001
\end{tabular}

Mean \pm SD. SJM, St Jude Medical; OMNI, Omnicarbon.

ID-2CTR-TAB17; GTCO CalComp, Inc, Columbia, Md), a microcomputer (Professional-380; Digital Equipment Corp, Maynard, Mass), and a specially designed computer program. The VTI of the pulsed wave Doppler recordings from the LVOT $\left(\mathrm{VTI}_{\mathrm{LVOT}}\right)$ and the VTI of continuous wave Doppler recordings of highest transprosthetic velocity $\left(\mathrm{VTI}_{\text {Peak }}\right)$ were computed. The stroke volume was calculated as the product of the cross-sectional area of the LVOT and $\mathrm{VTI}_{\text {LVOT }}$.

\section{Calculations}

Areas were calculated by means of either the peak velocity $\left(\mathrm{VTI}_{\text {Peak }}\right)$ across the valve $\left(\mathrm{EOA}_{\text {Peak }}\right)$ or separately for different orifices $\left(\mathrm{EOA}_{\text {Separate }}\right)$.

1. In vivo: $\mathrm{EOA}_{\text {Peak }}=$ Stroke volume/VTI $\mathrm{Veak}_{\text {Peak }}$

2. In vitro: $\mathrm{EOA}_{\text {Peak }}=$ Flow $/ \mathrm{VTI}_{\text {Peak }} / \mathrm{s}$

3. $\mathrm{EOA}_{\text {Separate }}=$ Fraction of flow/VTI $/$ Separate

4. Discharge coefficient $=\mathrm{EOA} / \mathrm{geometric}$ orifice area

\section{Statistics}

The results are expressed as the mean \pm SD. The mean of 3 Doppler measurements was used in patients with sinus rhythm and the mean of 10 measurements was used for patients in atrial fibrillation. The spread of data was expressed in percent as the coefficient of variation $(\mathrm{SD} /$ mean $\times 100 \%)$. The differences between the central and side orifices in the SJM valve and the major and minor orifices in the OMNI valve were tested with the use of a paired Student $t$ test. The difference between SJM and OMNI valves was tested by means of an unpaired Student $t$ test. The relationship between variables was assessed by linear regression.

\section{Results \\ The Proportion of the Forward Flow Entering Different Orifices}

In the SJM valve, the central orifice constitutes $25 \%$ of the full orifice area. In the OMNI valve, the minor orifice is $20 \%$ of the full orifice area.

\section{EOA in Vivo and in Vitro}

Figure 2 shows the relationship between prosthetic valve size size and EOA in vivo and in vitro. In vivo, valve size could explain $31 \%$ and $37 \%\left(R^{2}\right)$ of the variability in calculated EOA in the SJM and OMNI valves, respectively. A wide distribution was present, with the coefficient of variation $(\mathrm{SD} /$ mean $\times 100 \%)$ ranging from $21 \%$ to $39 \%$ for the $\mathrm{SJM}$ valve and from $25 \%$ to $33 \%$ for the OMNI valve. In vitro, valve size could explain $97 \%$ of the variability in EOA in both the SJM and OMNI valves. We observed a very narrow distribution, with coefficients of variation ranging from $1 \%$ to $7 \%$ in the SJM valve and from $1 \%$ to $5 \%$ in the OMNI valve. The discrepancies between geometric orifice valve areas and $\mathrm{EOA}_{\text {Peak }}$ were $0.96 \pm 0.49 \mathrm{~cm}^{2}$ for SJM versus $0.87 \pm 0.59$ $\mathrm{cm}^{2}$ for OMNI valves in vivo and $1.26 \pm 0.41 \mathrm{~cm}^{2}$ for SJM versus $1.17 \pm 0.38 \mathrm{~cm}^{2}$ for OMNI valves in vitro. 


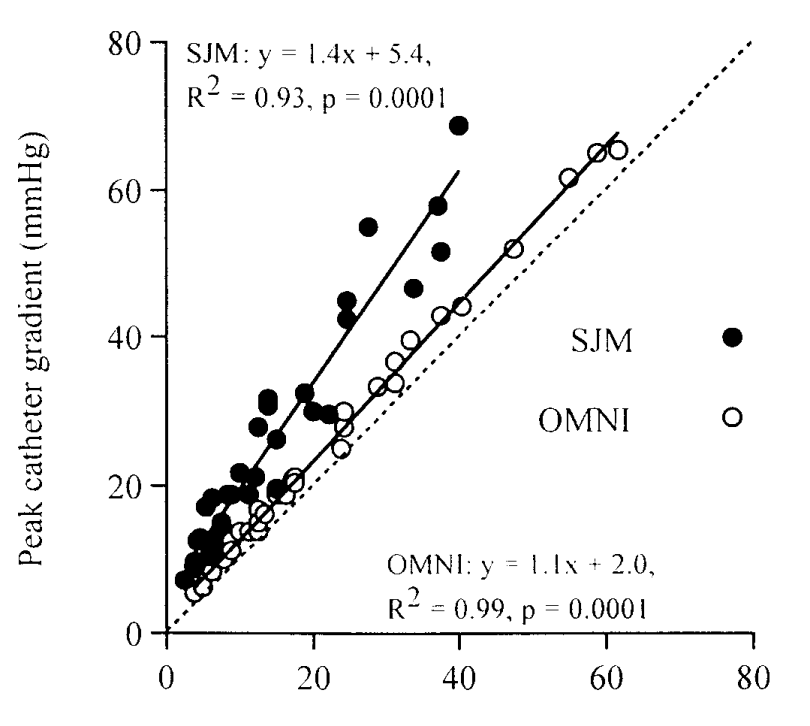

Net catheter gradient $(\mathrm{mmHg})$

Figure 3. Peak catheter gradients versus net catheter gradients in the St Jude Medical (SJM) and Omnicarbon (OMNI) valves. Mean difference between peak catheter gradient and net catheter gradient is $11.6 \pm 6.3 \mathrm{~mm} \mathrm{Hg}$ in St Jude Medical and $3.4 \pm 1.5 \mathrm{~mm} \mathrm{Hg}$ in Omnicarbon valves.

EOA and Discharge Coefficients Calculated Separately in Different Orifices

In the SJM valve (Table 1), the separate calculation of the EOA for different orifices increased the area significantly $(P$ $=.0001)$ because of higher central orifice velocity compared with the side orifice velocity $(2.4 \pm 0.7 \mathrm{~m} / \mathrm{s}$ vs $2.2 \pm 0.7 \mathrm{~m} / \mathrm{s}$; $P=.0001)$. The mean difference between the two methods was $0.14 \pm 0.09 \mathrm{~cm}^{2}$ (95\% confidence interval $0.10-0.17$ $\mathrm{cm}^{2}$ ). The overall increase in EOA was $9.6 \% \pm 5.0 \%$. In the OMNI valve, calculating the major and minor effective orifices separately did not change the total EOA. The mean difference between the two methods was $0.01 \pm 0.01 \mathrm{~cm}^{2}$. In the SJM valve, the side orifice had the highest discharge coefficient $(P=.0001)$, with an overall difference of 0.049 \pm 0.025 between the side and central orifices. In the OMNI valve, the difference between the major and minor orifices was small, $0.002 \pm 0.005(P=.03)$.

\section{EOA and Discharge Coefficients in SJM Versus OMNI Valves}

The overall volume flow was similar for SJM and OMNI valves $(304 \mathrm{~mL} / \mathrm{s}$ vs $305 \mathrm{~mL} / \mathrm{s} ; P=.96)$. The overall $\mathrm{EOA}_{\text {Peak }}$ was $1.35 \pm 0.37 \mathrm{~cm}^{2}$ and $1.45 \pm 0.49 \mathrm{~cm}^{2}$ for the SJM and OMNI valves, respectively $(P=.41)$. Calculating the orifice areas in the SJM valve separately increased the

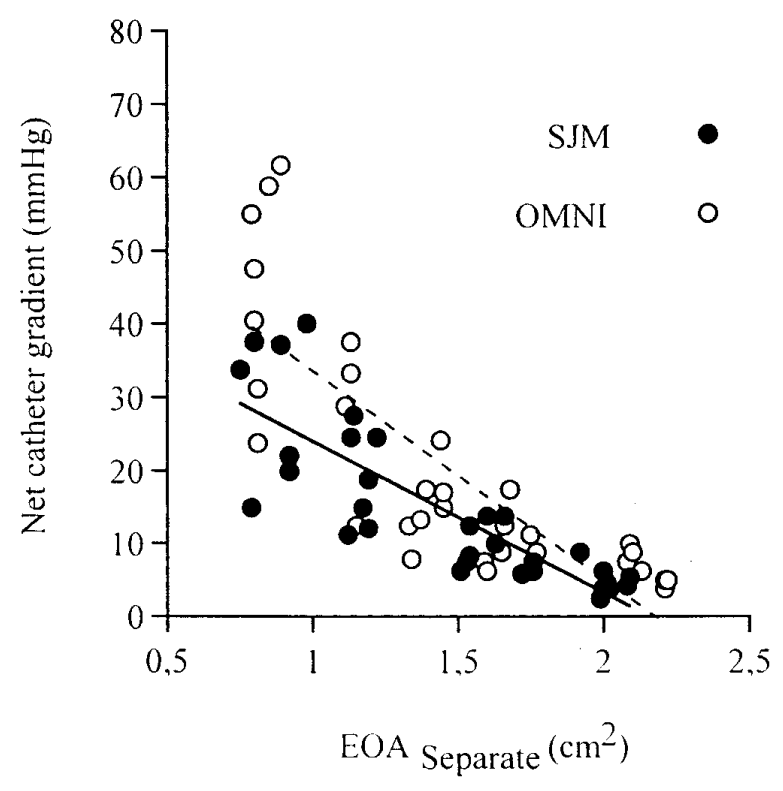

Figure 4. Relationship between peak EOA $\mathrm{Aeparate}$ and net catheter gradients. The St Jude Medical (SJM) $\left(y=-20.7 x+44.7, R^{2}=0.69\right.$, $P=.0001)$ and Omnicarbon (OMNI) $\left(y=-28.3 x+61.9, R^{2}=0.65, P=\right.$ $.0001)$ valves had a comparable effective orifice area (EOA), but the Omnicarbon valve had higher net catheter gradients than the St Jude Medical valve.

EOA to $1.49 \pm 0.45 \mathrm{~cm}^{2}$ in the SJM valve. The overall discharge coefficient using peak velocity for calculation was significantly lower in the SJM valve than in the OMNI valve $(0.52 \pm 0.03$ vs $0.56 \pm 0.022 ; P=.0001)$. When the EOA was calculated separately, the SJM discharge coefficient increased to $0.57 \pm 0.038$.

\section{Catheter Gradients Versus Doppler Areas}

The SJM and OMNI valves had similar peak catheter gradients (Table 2). However, pressure recovery was more pronounced in the SJM valve than in the OMNI valve. Figure 3 shows the relationship between peak and net catheter pressure gradients. The SJM and OMNI valves had comparable EOAs, but the OMNI valve had higher net catheter gradients than the SJM valve (Figure 4).

\section{Location of Peak Pressure in Different Orifices}

Table 3 shows the position of the peak catheter pressure gradient in relation to the prosthetic design and size. In the SJM valve, the peak pressure gradient was obtained at the entrance of the central orifice with pronounced pressure recovery within the central tunnel (Figure 5). In the side orifice, the pressure decreased less abruptly and the peak gradient was situated around the tip of the prosthetic leaflet. In the OMNI valve, the peak gradient was located near the 
TABLE 3. The position of peak catheter gradient in relation to prosthetic valve profile

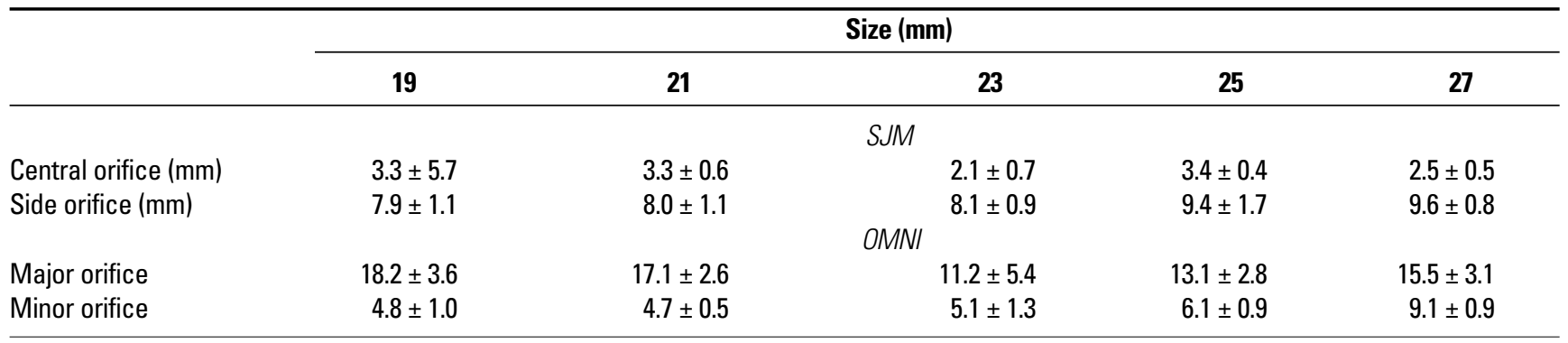

Mean \pm SD. SJM, St Jude Medical; OMNI, Omnicarbon. The catheter position is defined relative to the first structure in the prosthesis on the ventricular side.

entrance of the minor orifice and around the tip of the leaflet in the major orifice.

\section{Discussion}

The Doppler echocardiographic investigation of patients with prosthetic valves provides information relevant to the assessment of prosthetic valve function. The clinically most important question is whether or not the prosthetic valve is obstructed. With different valve designs (tilting disc, bileaflet, biologic), the extent to which the Doppler echocardiographic information can be used to describe hemodynamic performance and to compare one design with another is also important. The flow dependence of peak velocities and Bernoulli gradients limits their use. The EOA, calculated according to the continuity equation, is less flow dependent and therefore recommended in the assessment of prosthetic function. ${ }^{7}$ However, its usefulness rests with the freedom from, or existence of, other measurement errors, which we studied in the current investigation.

\section{Sources of Variation in EOA}

The EOA might vary in patients with the same prosthesis size because of true biologic variation, measurement errors, or underestimations or overestimations imposed when the prerequisites of the continuity principle are not fulfilled (Table 4).

The effect of subvalvular geometry on the size of the vena contracta has previously been described. ${ }^{13} \mathrm{~A}$ gradual narrowing favors a larger vena contracta compared with a more abrupt narrowing. Theoretically, therefore, some of the variation in EOA observed in vivo could be explained by the influence of the geometry of the LVOT.

Anatomic variation regarding the orientation of the annular ring and the surgeon's efforts to use the largest prosthetic valve might result in an oblique position of the valve relative to flow direction. This will reduce the EOA and could explain part of the variation observed in vivo. Further, in tilting disc valves, the orientation of the major and minor orifices might influence the relationship between leaflet and flow, and thereby the EOA, in an important manner. ${ }^{14,15}$
According to Table 4, measurement errors in the assessment of EOA are principally due to errors in the determination of LVOT area or angulation errors during the Doppler registration. In the in vitro study, we minimized both these errors, which may explain the very narrow spread in observed values for EOA.

According to the continuity principle, the velocity profile in both the subvalvular position and the prosthetic valve position must be uniform or flat. The subvalvular velocity profile has been investigated in patients with aortic stenosis ${ }^{16,17}$ and prosthetic valves. ${ }^{17}$ In prosthetic valves, the clinically obtained velocity with pulsed wave Doppler echocardiography was representative of the velocity profile in LVOT. ${ }^{17}$ However, there were individual differences, and these can explain cases of both overestimation and underestimation of EOA in our in vivo study. The velocity profile in prosthetic valves has been investigated by Yoganathan and associates ${ }^{18}$ using laser Doppler methods, which permits a detailed description of the spatial distribution of velocities. In bileaflet and tilting disc valves, they found relatively similar peak velocities in different orifices. However, these flow measurements were performed 8 to $11 \mathrm{~mm}$ downstream of the valve. The presence of higher velocities in the central orifice of the bileaflet valve has been documented previously by means of continuous wave Doppler recordings in the SJM valve. ${ }^{19}$ We were able to confirm this in the SJM valve, but in the OMNI valve we found similar velocities in the minor and major orifices. ${ }^{5}$ A possible effect of the nonuniformity of calculated EOA in the SJM valve has been postulated, ${ }^{6}$ but the magnitude has not been previously described. In the present study, we calculated the EOA for different orifices to evaluate the magnitude of error and found that, in overall terms, the total area increased by approximately $10 \%$.

In the in vitro study, we found for both the SJM and OMNI valves that a relatively small part of the geometric orifice area was used for forward flow with discharge coefficients ranging from 0.54 to 0.61 . The contraction of a jet through a constriction is dependent on orifice and LVOT geometry. ${ }^{20,21}$ In the model, the LVOT was conically shaped 

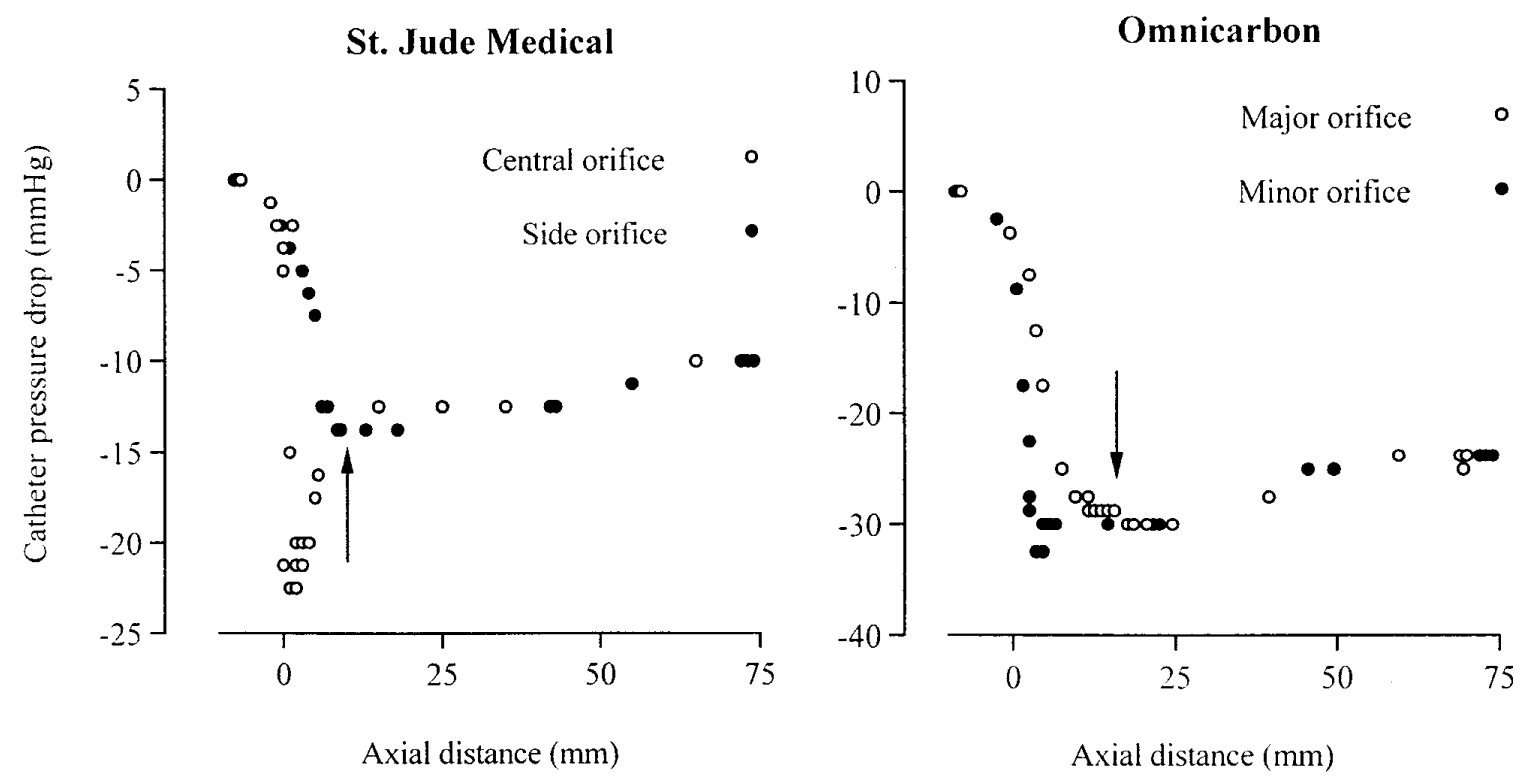

Figure 5. Pressure profiles obtained from catheter pullback in the central and side orifices of the St Jude Medical valve (size 23, left) and in the major and minor orifices of the Omnicarbon valve (size 21, right). Arrows indicate the distal part of the prosthesis. In the St Jude Medical valve the pressure drop is most pronounced in the proximal portion of the central orifice, with marked pressure recovery within the central tunnel.

to allow the fluid to enter the prosthesis smoothly, and we expected to find higher discharge coefficients. Using laser Doppler echocardiography, Shandas, Kwon, and Valdes$\mathrm{Cruz}^{22}$ found the vena contracta area in the side orifice of the SJM valve, which corresponds to the discharge coefficient, to be 0.94 . We therefore suspect that the calculated EOA and discharge coefficients, even after corrections for higher central velocities in the SJM valve, underestimate the actual EOA. Underestimation of flow and overestimation of peak velocity are possible sources of a systematic underestimation of the EOA in the in vitro study. The flow measurements (Transonic Systems, Inc) were calibrated with timed collections as a reference, with a strong linear relationship. The spatial velocity profile has been described downstream in the aorta with laser Doppler echocardiography ${ }^{18,23}$ but, to our knowledge, not within the prosthetic valves. It is conceivable that the velocity profile in the different orifices is not laminar or flat. Therefore, the most likely source of error is that the peak velocity overestimates the spatial velocity profile.

\section{Hemodynamic Performance}

Today, Doppler gradients and EOAs are frequently used to describe the hemodynamic performance of prosthetic valves and to compare one design with another. The limitations of Doppler gradients in the assessment of prosthesis performance have previously been demonstrated., 4,24 The degree of pressure recovery varies and depends on valve design, 5,24 size,${ }^{5}$ and aortic root dimensions. ${ }^{19}$ It is generally accepted that the net gradient is the gradient of interest in describing the hemodynamic performance of a prosthetic valve. ${ }^{25}$ In the present study, we found that the EOA in the SJM and OMNI valves was similar, but the SJM valve had more pronounced pressure recovery and lower net gradients than the OMNI valve. This finding therefore indicates that the EOA is also of limited value in the assessment of prosthetic hemodynamic performance.

\section{Location of the Vena Contracta}

In the present study, we determined the position of the peak pressure gradient within the different orifices. These gradients correspond to the location of the vena contracta. In the SJM valve, the smallest flow area lies a few millimeters from the proximal tip of the valve, with marked pressure recovery, and we can assume an increase in flow area within the central tunnel. In a recent report by Shandas, Kwon, and Valdes-Cruz, ${ }^{22}$ the EOA in the SJM valve was determined with laser Doppler echocardiography in the distal vicinity of the prosthesis. The authors propose that these measurements can be used as reference data. However, our data indicate that this method overestimates the central area of the prosthesis.

\section{Study limitations}

Recent knowledge shows that, in tilting disc valves like the OMNI valve, the surgeon should try to orient the leaflet in the 


\section{TABLE 4. Principal causes of the variation in EOA within the same valve size according to the continuity principle}

\begin{tabular}{|c|c|}
\hline Cause for variation & Result \\
\hline \multicolumn{2}{|l|}{ True biologic variation in EOA within the same valve size group } \\
\hline Subvalvular geometry might influence the size of the vena contracta & Decrease in EOA \\
\hline Tilting of the prosthesis & Decrease in EOA \\
\hline Orientation of the monoleaflet & Decrease in $\mathrm{EOA}$ \\
\hline \multicolumn{2}{|l|}{ Errors in measurement } \\
\hline Incorrect LVOT area & Overestimation or underestimation of EOA \\
\hline Angulation error in $\mathrm{V}_{\mathrm{LVOT}}$ & Underestimation of EOA \\
\hline Angulation error in $\mathrm{V}_{\text {Peak }}$ & Overestimation of EOA \\
\hline \multicolumn{2}{|l|}{ Prerequisites of the continuity principle not fulfilled } \\
\hline Nonuniformity in subvalvular velocity profile & Overestimation or underestimation of EOA \\
\hline Nonuniformity in prosthetic velocity profile & Underestimation of EOA \\
\hline
\end{tabular}

$E O A$, Effective orifice area; $L V O T$, left ventricular outflow tract; $V_{L V O T}$, blood velocity in the left ventricular outflow tract; $V_{P_{\text {eak }}}$, peak velocity.

flow direction to minimize the flow disturbance and energy loss. ${ }^{14,15}$ This usually means that the major orifice is oriented to the right and, dependent on the flow direction, the disc does not necessarily open completely. In the in vitro model, the prosthetic valves were mounted with the sewing ring perpendicular to the flow direction. In the period 1991 to 1993, when the study patients were operated on, the importance of valve orientation was not recognized. Therefore, in both the in vivo and in vitro studies, the position of the OMNI valve might be suboptimal, and this may have increased the flow velocities and reduced the calculated EOA.

We used a steady-flow model, and the possible effects of differences in prosthetic leakage cannot be evaluated. It is therefore impossible to compare the SJM and OMNI valves from our data and to draw any conclusions about which is the better prosthesis.

Although it was not verified that the SD was proportional to the measured area, the coefficient of variation was used to elucidate the large variation in valve areas within each valve size group.

\section{Clinical Implications}

With Doppler echocardiography, prosthetic valve function can be assessed semiquantitatively. Using reference values specified for valve design and size and, if available, comparing the observed values with a previous investigation provide an instrument for detecting prosthetic dysfunction. ${ }^{10}$ However, Doppler echocardiographic data, both flow dependent and flow independent, can be misleading in the assessment of prosthetic performance when bileaflet and tilting disc valves are compared.

Anders Odén gave statistical advice. We thank the personnel at the Departments of Biomedical Engineering and Clinical Physiology, Linköping University Hospital, for their skillful model construction and help during tests.

\section{References}

1. Verheul HA, van den Brink RBA, Bouma BJ, Hoedemaker G, Moulijn AC, Dekker E, et al. Analysis of risk factors for excess mortality after aortic valve replacement. J Am Coll Cardiol. 1995;26:1280-6.

2. Abdelnoor M, Nitter-Hauge S, Trettli S. Relative survival of patients after heart valve replacement. Eur Heart J. 1990;11:23-8.

3. Rahimtoola S. The problem of valve prosthesis-patient mismatch. Circulation. 1978;58:20-4.

4. Baumgartner H, Khan S, DeRobertis M, Czer L, Maurer G. Discrepancies between Doppler and catheter gradients in aortic prosthetic valves in vitro: a manifestation of localized gradients and pressure recovery. Circulation. 1990;82:1467-75.

5. Bech-Hanssen O, Caidahl K, Wallentin I, Brandberg J, Wranne B, Ask P. Aortic prosthetic valve design and size: relation to Doppler echocardiographic findings and pressure recovery-an in vitro study. $J \mathrm{Am}$ Soc Echocardiogr. 2000;13:39-50.

6. Baumgartner H, Khan SS, DeRobertis M, Czer LS, Maurer G. Doppler assessment of prosthetic valve orifice area. Circulation. 1992:85:2275-83.

7. Chambers J, Fraser A, Lawford P, Nihoyannopoulos P, Simpson I. Echocardiographic assessment of artificial heart valves: British Society of Echocardiography position paper. Br Heart J. 1994;71:6-14.

8. Gorlin R, Gorlin SG. Hydraulic formula for calculation of the area of the stenotic mitral valve, other cardiac valves, and central circulatory shunts. I. Am Heart J. 1951;41:1-29.

9. Chafizadeh ER, Zoghbi WA. Doppler echocardiographic assessment of the St. Jude Medical prosthetic valve in the aortic position using the continuity equation. Circulation. 1991;83:213-23.

10. Bech-Hanssen O, Wallentin I, Larsson S, Caidahl K. Reference Doppler echocardiographic values for St. Jude Medical, Omnicarbon and Biocor prosthetic valves in the aortic position. J Am Soc Echocardiogr. 1998;11:466-77.

11. Peter M, Weiss P, Jenzer HR, Hoffmann A, Dubach P, Roth J, et al. The Omnicarbon tilting-disc heart valve prosthesis: a clinical and Doppler echocardiographic follow-up. J Thorac Cardiovasc Surg. 1993; 106:599-608.

12. Skjaerpe T, Hegranaes L, Hatle L. Noninvasive estimation of valve area in patients with aortic stenosis by Doppler ultrasound and twodimensional echocardiography. Circulation. 1985;72:810-8.

13. Baumgartner H, Schima H, Tulzer G, Kuhn P. Effect of stenosis geometry on the Doppler-catheter gradient relation in vitro: a manifestation of pressure recovery. J Am Coll Cardiol. 1993;21:1018-25.

14. Travis BR, Heinrich RS, Ensley AE, Gibson DE, Hashim S, Yoganathan AP. The hemodynamic effects of mechanical prosthetic valve type and orientation on fluid mechanical energy loss and pressure drop in in vitro models of left ventricular hypertrophy. $J$ Heart Valve Dis. 1998;7:345-54. 
15. Kleine P, Perthel M, Nygaard H, Hansen SB, Paulsen PK, Riis C, et al. Medtronic Hall versus St. Jude Medical mechanical aortic valve: downstream turbulences with respect to rotation in pigs. J Heart Valve Dis. 1998;7:548-55.

16. Sjöberg BJ, Ask P, Loyd D, Wranne B. Subaortic flow profiles in aortic valve disease: a two-dimensional color Doppler study. J Am Soc Echocardiogr. 1994;7:276-85.

17. Wiseth R, Samstad S, Rossvoll O, Torp HG, Skjaerpe T, Hatle L. Cross-sectional left ventricular outflow tract velocities before and after aortic valve replacement: a comparative study with two-dimensional Doppler ultrasound. J Am Soc Echocardiogr. 1993;6:279-85.

18. Yoganathan AP, Sung H-W, Woo Y-R, Jones M. In vitro velocity and turbulence measurements in the vicinity of three new mechanical aortic heart valve prostheses: Björk-Shiley Monostrut, Omni-Carbon, and Duromedics. J Thorac Cardiovasc Surg. 1988;95:929-39.

19. Vandervoort PM, Greenberg NL, Pu M, Powell KA, Cosgrove DM, Thomas JD. Pressure recovery in bileaflet heart valve prostheses. Circulation. 1995;92:3464-72.

20. Yoganathan AP, Cape EG, Sung H-W, Williams FP, Jimoh A. Review of hydrodynamic principles for the cardiologist: applications to the study of blood flow and jets by imaging techniques. J Am Coll Cardiol. 1988;12:1344-53.

21. Flachskampf FA, Weyman AE, Guerrero JL, Thomas JD. Influence of orifice geometry and flow rate on effective valve area: an in vitro study. J Am Coll Cardiol. 1990;15:1173-80.

22. Shandas R, Kwon J, Valdes-Cruz L. A method for determining the reference effective flow areas for mechanical heart valve prostheses. Circulation. 2000;101:1953-9.

23. Yoganathan AP, Chaux A, Gray RJ, Woo YR, DeRobertis M, Williams FP, et al. Bileaflet, tilting disc and porcine aortic valve substitutes: in vitro hydrodynamic characteristics. J Am Coll Cardiol. 1984;3:313-20.

24. Baumgartner H, Khan S, DeRobertis M, Cser L, Maurer G. Effect of prosthetic aortic valve design on the Doppler-catheter gradient correlation: an in vitro study of normal St. Jude, Medtronic-Hall, StarrEdwards and Hancock valves. J Am Coll Cardiol. 1992;19:324-32.

25. Khan SS. Assessment of prosthetic valve hemodynamics by Doppler: lessons from in vitro studies of the St. Jude valve. J Heart Valve Dis. 1993;2:183-93.

\section{Availability of Journal back issues}

As a service to our subscribers, copies of back issues of The Journal of Thoracic and Cardiovascular Surgery for the preceding 5 years are maintained and are available for purchase from Mosby until inventory is depleted. Please write to Mosby, Subscription Customer Service, 6277 Sea Harbor Dr, Orlando, FL 32877, or call 800-654-2452 or 407-345-4000 for information on availability of particular issues and prices. If unavailable from the publisher, photocopies of complete issues may be purchased from Bell \& Howell Information and Learning, $300 \mathrm{~N}$ Zeeb Rd, Ann Arbor, MI 48106-1346; 734-761-4700 or 800-521-0600. 